\title{
OS TUPI GUARANI DA ALDEIA RENASCER (SP): UMA REFLEXÃO SOBRE OS ENUNCIADOS DA MISTURA E OS AGENCIAMENTOS DA "CULTURA"1
}

\author{
AMANDA CRISTINA DANAGA ${ }^{2}$ \\ UFSCAR
}

\begin{abstract}
RESUMO: Esse artigo visa discutir a interlocução da aldeia Renascer com os outros (índios e não índios) dentro do contexto de produção da "cultura". A aldeia em questão fica no município de Ubatuba e formou-se a partir da ocupação de uma aldeia cenográfica, utilizada nas filmagens do longa-metragem "Hans Staden". Na aldeia residem índios Tupi Guarani e Guarani Mbya, e, assim como as demais aldeias da região, Renascer está inserida no "universo dos projetos" na busca por maior visibilidade no cenário político nacional e nos investimentos, para tornar aparentes as singularidades de sua "cultura". Na Aldeia Renascer os Tupi Guarani e Guarani Mbya (apesar das diferenças que destacam entre si) se organizam e se complementam em torno dos aspectos políticos e religiosos de suas comunidades, agenciando o discurso da "cultura", principalmente, na interação com o mundo dos não índios, ao requererem seus direitos territoriais e reconhecimento em vários aspectos.
\end{abstract}

PALAVRAS-CHAVE: Tupi Guarani; Guarani Mbya; mistura; “cultura”.

ABSTRACT: This paper aims to discuss the dialogue between the Renascer Village and other people (indians or non-indians) inside the context of production of "culture". The village called in question is settled in Ubatuba and was formed from the occupation of a scenographic village built as film set for the filming of the feature film "Hans Staden". In the village reside Tupi Guarani and Guarani Mbya Indians. Like other villages in the region, Renascer is included into the "universe of projects" in search of greater visibility on the national political scene and investments in order to make visible particularities of their "culture". In the Renascer Village the Tupi Guarani and Guarani Mbya (despite the differences that stand between them) are organized and complement themselves around the political and religious aspects of their communities, touting the discourse of "culture", especially in interaction with the world of nonindians, requiring their territorial rights and recognition in several aspects.

\footnotetext{
${ }^{1}$ Este artigo é parte de uma reflexão iniciada em minha dissertação de mestrado "Os Tupi, os Mbya e os outros: um estudo etnográfico da Aldeia Renascer - Ywyty Guaçu”, sob orientação do Prof. Dr. Edmundo Antônio Peggion. Este trabalho foi, ainda, apresentado na $28^{a}$ Reunião Brasileira de Antropologia - RBA, no grupo de trabalho "Novos Olhares sobre os Guarani", coordenado por Valéria Macedo (UNIFESP) e Elizabeth Pissolato (UFJF). Agradeço a Elisabeth Pissolato pela leitura e considerações e também a Valéria Macedo por suas contribuições na ocasião do evento da $28^{\mathrm{a}} \mathrm{RBA}$ e pela posterior leitura e sugestões para o texto.

${ }^{2}$ Cursou graduação em Ciências Sociais pela Universidade Estadual Paulista Júlio de Mesquita Filho UNESP e mestrado em Antropologia Social pela Universidade Federal de São Carlos - UFSCar. Atualmente cursa o doutorado no Programa de Pós Graduação em Antropologia Social da UFSCar. Tem experiência na área de Antropologia, com ênfase em Etnologia Indígena, atuando principalmente nos seguintes temas: etnologia, aldeia Renascer, aldeia Piaçaguera e Tupi Guarani. E-mail: adanaga@gmail.com .
}

Espaço Ameríndio, Porto Alegre, v. 6, n. 2, p. 10-31, jul./dez. 2012. 
AMANDA CRISTINA DANAGA - Os Tupi Guarani da Aldeia Renascer (SP)...

KEYWORDS: Tupi Guarani; Guarani Mbya; mixture; "culture".

\section{Contextualização do campo}

As produções etnográficas acerca das populações indígenas no Brasil, durante as décadas de 60 e 70 do século XX, estiveram voltadas, sobretudo, aos estudos de grupos do Brasil Central. Sobre os povos Tupi, há um vasto material existente, porém mais direcionado aos povos Amazônicos. A retomada nas pesquisas dos povos Tupi aconteceu com os estudos de Eduardo Viveiros de Castro (1986) sobre o povo Araweté, grupo Tupi da Amazônia (VIVEIROS DE CASTRO, 1986).

Em relação aos povos Tupi que viviam em aldeias no estado de São Paulo, as pesquisas eram escassas. Havia um foco maior voltado para os Guarani do Sul do Brasil e do Paraguai.

Durante a década de 80 , a visão predominante em relação às aldeias nas quais viviam os índios do estado de São Paulo era de que as mesmas estariam fadadas ao desaparecimento. A dissipação dessa população, bem como de sua cultura, seria inevitável, devido ao convívio próximo a contextos urbanos e o uso da mão de obra indígena nessas cidades. Estes se apresentariam como os principais fatores responsáveis por integrá-los, cada vez mais, à sociedade nacional. Contrariamente ao que propunha esse pensamento pelo viés da aculturação, viu-se $o$ aparecimento de muitas aldeias e o crescimento das aldeias já existentes. As migrações realizadas pelos Guarani Mbya, vindos do Sul do Brasil e de países vizinhos, como Argentina e Paraguai - em direção ao litoral do estado de São Paulo -, também contribuíram para o aumento e a formação de novas aldeias nessa região.

Dados do Instituto Brasileiro de Geografia e Estatística (IBGE) apontam uma população de 39.794 índios vivendo no estado de São 
AMANDA CRISTINA DANAGA - Os Tupi Guarani da Aldeia Renascer (SP)...

Paulo de acordo com o censo demográfico realizado em 20103. A maioria desses índios é composta pelas etnias Guarani Mbya e Nhandeva, embora também exista a presença de outras etnias no estado, como, por exemplo, Kaingang, Krenak e Terena (principalmente no interior do estado). Essa população encontra-se distribuída em aldeias localizadas na região Metropolitana de São Paulo, no Oeste do estado, na Baixada Santista, no litoral Sul e Norte paulista e na região do Vale do Ribeira.

O surgimento de novas aldeias e o crescimento de aldeias já existentes, após a década de 80 , foi bastante significativo na região que abrange o sudeste do Brasil, especialmente na faixa que se estende pelo litoral do estado de São Paulo. Essas aldeias se formaram dentro de um contexto de ocupação de territórios que esses grupos reconhecem como tradicionais. Uma significativa parte desses índios provém de aldeamentos mais antigos da região, como o aldeamento do Bananal (Peruíbe), Serra do Itatins (Itariri) e Rio Branco (Itanhaém). De acordo com relatos, divergências e conflitos de diversas ordens provocaram a disseminação desses índios por todo o litoral paulista.

O caso de formação da aldeia Renascer não é singular, se observado como parte de um contexto maior que remonta a uma série de eventos de retomada de territórios tidos como tradicionais nessa região. Esse movimento tem sido uma prática comum entre os índios Tupi Guarani nas últimas décadas, empenhados na tentativa de reocupar terras onde eles afirmam já terem vividos seus antepassados.

A investigação sobre a constituição dessas diversas aldeias que se formaram na faixa litorânea do sudeste do Brasil permitiu observar a existência do agenciamento de um discurso de reivindicação de uma autodenominação, até então desconsiderada pela literatura etnográfica da região: a Tupi Guarani. Residentes dessas aldeias identificam suas origens como resultado de uma mistura entre povos distintos: os Tupi, destacando os Tupiniquins e os Tupinambá; e os Guarani, que vieram chegando posteriormente ao litoral, em decorrência das migrações na busca da Terra Sem Males (CLASTRES, H. 1978).

\footnotetext{
${ }^{3}$ Os números citados acima referem-se a população indígena do estado de São Paulo com 5 anos de idade ou mais, de acordo com os dados disponibilizados pelo IBGE do censo de 2010. No censo realizado no ano de 2000, considerando a totalidade da população indígena do estado de São Paulo (sem restrição de idade), registrou-se uma população de 63.789 índios (http://ibge.gov.br/home/).
} 
AMANDA CRISTINA DANAGA - Os Tupi Guarani da Aldeia Renascer (SP)...

A extensa literatura etnográfica desde muito tempo se refere a esses grupos como sendo apenas Guarani, mais especificamente Guarani Nhandeva ou Xiripá (SCHADEN, 1974).

No entanto, logo no início de minhas pesquisas com grupos que habitam o litoral do estado de São Paulo, ao longo de conversas motivadas em visitas a aldeias, eles mostraram claramente o desejo de reivindicar e reafirmar sua autodesignação enquanto Tupi Guarani, observando diferenças com relação aos Guarani e enfatizando sua ascendência Tupi. Sendo assim, eles se consideram uma mistura resultante dos casamentos que ocorreram entre aos dois grupos e aplicam a designação Tupi Guarani, que até então era um conceito que servia para caracterizar uma família linguística, como um atributo de um discurso de identificação. Ressaltam, ainda, as distinções linguísticas, sociais, materiais e culturais que expressam diante dos índios Guarani Mbya, com quem compartilham diversas aldeias.

Existe uma conexão entre as diversas aldeias Tupi Guarani que traduz um modelo de organização que é próprio desse grupo. As relações entre essas aldeias são pautadas pelo parentesco, no estabelecimento das alianças, pelos pontos que eles marcam como sinalizadores de sua identidade (tais como uma língua comum), pelas diferenças em relação aos Guarani Mbya, sobretudo no que refere à questão da mobilidade, e pela realização de visitas recorrentes que ocorrem entre os índios Tupi Guarani de diferentes lugares (PEGGION et al., 2008) 4.

Ladeira e Azanha (1988) já apontavam o uso da denominação Tupi Guarani por alguns índios. Conforme eles escreveram, a população indígena do grupo conhecido como Guarani Nhandeva, que

\footnotetext{
${ }^{4} \mathrm{O}$ tema da mobilidade entre os Guarani é muito discutido e abordado pela literatura etnológica acerca dos povos Tupi-Guarani (NIMUENDAJU, 1987; MÉTRAUX, 1979; P. CLASTRES, 1990; H. CLASTRES, 1978; CADOGAN, 1997; SCHADEN, 1974; MELIÀ, 1991, entre outros). Vinculados inicialmente à religião, os movimentos territoriais estavam associados ao mito da busca pela terra sem mal. Em abordagens mais recentes, esses deslocamentos estão articulados a uma procura pelo "modo de ser", o teko. Com o trabalho de Pissolato (2007) a ligação restrita entre mobilidade e religião é ampliada. A mobilidade passa a ser vista, de acordo com a autora, como resultado de uma decisão individual, fazendo parte das histórias de vida de cada um, onde os sujeitos procuram uma satisfação pessoal na busca da duração da pessoa. Nesse sentido, ao deslocar-se, mesmo que por razões individuais, o sujeito operaria em uma atualização do parentesco, que pode ser sempre reformulado na medida em que as relações se estendem em um universo "multilocal", como ressaltou a autora, é uma espécie de parentesco que está sempre por se fazer.
}

Espaço Ameríndio, Porto Alegre, v. 6, n. 2, p. 10-31, jul./dez. 2012. 
AMANDA CRISTINA DANAGA - Os Tupi Guarani da Aldeia Renascer (SP)...

habitava o litoral, era denominada pelos índios Mbya como Xiripá ou Tupi Guarani. A designação Xiripá é muito usada, ainda hoje, pelos Mbya ao referirem-se aos Nhandeva e aos Tupi Guarani, que por sua vez também não se identificam com tal denominação, afirmando que esse nome se refere a uma vestimenta antiga produzida de embira, encarando a denominação como uma injúria.

Pesquisas recentes têm levado em consideração essa autodenominação requerida por muitos índios do litoral. Mainardi (2010)5, em sua dissertação de mestrado, abordou o tema da mistura entre os grupos Tupi e Guarani, que deu origem a uma nova categoria de identificação: os Tupi Guarani. Ela analisa como os Tupi Guarani da aldeia Piaçaguera, no litoral sul do estado de São Paulo, edificam suas relações com os outros indígenas, sobretudo com os Guarani Mbya. Pautados pelo discurso da mistura, os Tupi Guarani estabelecem o que ela define como uma espécie de progressão entre "mais índio" e "menos índio", progressão essa atrelada a peculiaridades típicas da tradição guarani.

Ser "mais índio" implica em estar adaptado à vida na aldeia, ao contato com a natureza, ao falar a língua, a fazer roça e saber caçar, entre tantas características tidas como indígenas. Tais caracteres permitem que se estabeleça algo como uma espécie de gradação entre o "mais índio" e o "menos índio". Ainda que esses pólos não sejam bem delimitados e que seu uso seja contextual, pode-se situar os Tupi Guarani e os Mbya entre eles, sendo que o primeiro encontra-se em posição desfavorecida, mais próximo do "menos índio", ou "menos puro", e o último perto do "mais índio". [...] Assim, determinados modos de agir dos Tupi Guarani são vistos como "mais guarani" ou "mais indígenas". No limite, no entender dos Tupi Guarani, características Guarani e índias estão associadas. O modo de ser, a mobilidade, a relação com a terra dos Guarani estão vinculados à idéia que os Tupi Guarani constroem acerca do que é ser índio (MAINARDI, 2010, p.58; p.64).

Macedo (2009, p.79), em pesquisa realizada na Terra Indígena

\footnotetext{
${ }^{5}$ Camila Mainardi é antropóloga e pesquisadora dos Tupi Guarani. Foi companheira no trabalho de campo realizado na aldeia Piaçaguera (2007/2008). Atualmente faz doutorado em Antropologia Social no Programa de pós Graduação da Universidade de São Paulo (PPGAS - USP).
}

Espaço Ameríndio, Porto Alegre, v. 6, n. 2, p. 10-31, jul./dez. 2012. 
AMANDA CRISTINA DANAGA - Os Tupi Guarani da Aldeia Renascer (SP)...

Ribeirão Silveira, reconhece que há essa atribuição e salienta que "[...] os Mbya que vieram do Sul chamam os que na literatura são designados Nhandeva de Xiripá, mas os que vivem no estado de São Paulo são chamados, e se autodesignam, Tupi ou Tupi-Guarani".

\section{Sobre a categoria Nhandeva}

Diante das definições apresentadas nas discussões etnográficas e das alcunhadas pelos próprios índios sobre o termo Nhandeva, podemos engendrar alguns questionamentos acerca da acepção dessa categoria: O termo Nhandeva faz alusão ao mesmo tipo de gente? Ou seria usado para definir um tipo de outro que é igual a nós, dependendo de certos contextos enunciativos e dos contrastes que ser quer estabelecer?

Essa denominação faz parte da divisão criada por Schaden (1974) para fazer referência aos Guarani. O autor elaborou essa divisão com base nas distinções observadas entre esses grupos, bem como suas especificidades linguísticas e de sua organização social, política, religiosa, econômica e cultural. Mas o próprio autor também reconhece que a categoria Nhandeva é utilizada em sentido mais amplo, ela é uma denominação empregada por todos os índios do grupo Guarani que exprime o sentido de dizer os que são dos nossos. Nesse sentido o mesmo autor se refere a essa categoria como uma autodenominação usada pelos grupos que eram conhecidos como Apapocuva, Tanyguá e Oguauíva. Nhandeva, de acordo com Schaden (1974), seria uma forma de autorreferência empregada por esses subgrupos Guarani.

Era comum, ao longo das visitas realizadas durante o meu trabalho de campo, chegar a uma aldeia e observar todos olharem curiosos para ver de quem se tratava e, logo que avistavam um ou mais índios em minha companhia, se ouvia dizer: "É Nhandeva!".

O que pude observar entre os Tupi Guarani que habitam o litoral paulista é que eles parecem se valer da categoria Nhandeva não como uma autodenominação que remeta a uma etnia específica, conforme consta na literatura etnográfica, mas sim como uma forma de identificar-se enquanto índios, empregando o termo, 
AMANDA CRISTINA DANAGA - Os Tupi Guarani da Aldeia Renascer (SP)...

em certas ocasiões, em oposição ao não índio. Isso permite considerar a categoria Nhandeva como uma noção relacional, sujeita aos contextos e aos atores em jogo.

Macedo (2009), em alusões feitas sobre as preferências matrimoniais do Guarani Mbya, comenta que as uniões com os brancos costumam ser mais controversas do que com os Nhandeva, ou Tupi, já que os "[...] Mbya e Nhandeva, mesmo que não se considerem afins ideais, se reconhecem como a mesma modalidade de gente, nhandeva'e" (MACEDO, 2009, p.38).

Ladeira (2008) também ressalta que a denominação Nhandeva não é uma forma de autorreferência utilizada por esses índios (Tupi Guarani), mas uma denominação que foi apropriada por eles na relação com os não índios.

Corroborando com Mainardi (2010), no caso dos Tupi Guarani, apesar dessa afirmação de uma denominação e de uma cultura própria, a categoria Nhandeva não recusa a denominação Tupi Guarani, pelo contrário, ela compreende todos os demais índios.

Apesar dos projetos que visam afirmar uma identidade e cultura Tupi Guarani, é importante dizer que ser Nhandeva não exclui ser Tupi Guarani, pelo contrário engloba, além dos Tupi Guarani, todos os outros índios (MAINARDI, 2010, p.23).

De acordo com Viveiros de Castro (1996), grande parte dos nomes aplicados aos grupos ameríndios nada tem a ver com uma autodenominação. Eles são atribuições dadas por outros povos e constituem-se, em muitas ocasiões, em termos pejorativos carregados de ofensas a esses grupos. Nessa discussão o etnônimo consiste em um nome dado por outro, o que o torna parte da categoria eles e não nós, registrando o ponto de vista daquele que atribui a nominação. A partir das reflexões de Viveiros de Castro (1996), pode-se considerar que a categoria Nhandeva indica, então, uma "posição de sujeito", um "marcador enunciativo, não um nome". Segundo o autor, as categorias do pensamento ameríndio não compreendem os mesmos sentidos ou premissas do pensamento que as criou, ou seja, do pensamento ocidental. 
AMANDA CRISTINA DANAGA - Os Tupi Guarani da Aldeia Renascer (SP)...

[...] as categorias indígenas de identidade coletiva têm aquela enorme variabilidade contextual de escopo característica dos pronomes, marcando contrastivamente desde a parentela imediata de um Ego até todos os humanos, ou mesmo todos os seres dotados de consciência; sua coagulação como "etnônimo" parece ser, em larga medida, um artefato produzido no contexto da interação com o etnógrafo (VIVEIROS DE CASTRO, 1996, p. 125).

Assim, a posição do sujeito é definida diante do uso que os nativos fazem do termo Nhandeva, geralmente para determinar aqueles que são dos nossos, em boa parte dos casos observados, contrastando com os não indígenas.

\section{A aldeia Renascer (Ywyty Guaçu)}

A aldeia Renascer formou-se em setembro de 1999 com a chegada ao local de algumas famílias Tupi Guarani e Guarani Mbya, sob a liderança do Tupi Antonio Silva Awá, então cacique da aldeia. Na ocasião, essas pessoas haviam sido convidadas para participarem das gravações do filme de Luis Alberto Pereira, intitulado "Hans Staden". O local onde hoje se situa a aldeia foi o cenário utilizado para a produção do longa-metragem. Foram construídas grandes ocas cenográficas, na tentativa de remeter a uma aldeia tradicional dos índios Tupinambás que habitavam a costa litorânea brasileira durante o século XVI. O filme produzido na aldeia contou com a participação de alguns índios que fizeram apenas papéis figurativos e um deles foi Antonio Awá.

Durante o trabalho de campo na aldeia Renascer, as pessoas que hoje residem na área indicaram que o filme teve um papel secundário na formação da aldeia. Segundo elas, o filme foi um veículo pelo qual as famílias, engajadas em projetos de preservação da tradição na reocupação de territórios tradicionais, puderam se encontrar e realizar um desejo que lhes era comum. Assim, o cacique Awá tinha um propósito e acabou por encontrar outras famílias que apresentavam o mesmo propósito. Ele alega que o filme foi apenas um cenário que favoreceu a realização de suas intenções. 
AMANDA CRISTINA DANAGA - Os Tupi Guarani da Aldeia Renascer (SP)...

De acordo com Antonio Awá, Nhanderu havia revelado através de um sonho para sua mãe que ali era um bom lugar6. A mãe de Awá, Luzia Samuel dos Santos (também conhecida como Penha), nasceu e foi criada na aldeia do Bananal e é filha de Samuel Américo dos Santos, ambos já falecidos. Segundo as considerações levantadas por Antonio Awá, Ubatuba era uma região muito almejada por sua mãe, que sonhava em um dia residir no local. Após sonhar com sua mãe, indicando sua vinda para essa região, ele se mudou para Ubatuba. Quando surgiu a oportunidade de participar do filme foi que Awá conheceu o lugar no qual, em seguida, fundaria a aldeia Renascer. Houve uma grande identificação entre o local conhecido e o local apontado em sonho por sua mãe. Em virtude disso, juntamente com outros índios, Awá optou por permanecer na área, habitando, inicialmente, o cenário.

Contam que, no início das gravações, houve uma promessa para construção de um lugar destinado ao turismo na área, dedicando uma das ocas cenográficas para produção e comercialização dos artesanatos produzidos pelos índios da região. Seria um espaço turístico destinado a promoção da cultura indígena, o que não se concretizou. Essa teria sido uma promessa feita pela Prefeitura do Município de Ubatuba (que na época era administrada pelo prefeito Euclides Luiz Vigneron, mais conhecido como Zizinho) aos índios, mas não há nada documentado nesse sentido. Embora digam que havia reportagens de jornal desse período registrando a promessa feita pela Prefeitura, não foi possível encontrá-las nos arquivos municipais. Encontrei apenas uma fala do próprio diretor do filme remetendo-se ao assunto. Ele diz: "Uma pessoa tinha combinado com a Prefeitura de Ubatuba manter a aldeia [referindo-se a aldeia cenográfica] como uma espécie de Museu e ela foi ficando, mas depois não fizeram mais nada" (PEREIRA, 2000).

A entrada no espaço onde o filme foi produzido não aconteceu

\footnotetext{
${ }^{6}$ A discussão acerca da importância dos sonhos para os Guarani está muito presente na literatura etnográfica. Pissolato (2007) diz que, para os Mbya, o sonho funciona como uma interpretação de uma mensagem divina, indicando caminhos, ações e aconselhando, por isso, recomenda-se contar o sonho, preferencialmente para um tamõi (pessoa mais velha; xamã) ou um xamã. Ele pode orientar uma coletividade e dar impulso a acontecimentos maiores, como por exemplo, a escolha de lugares para formação de aldeias. "[...] o sonho é por excelência matéria de interpretação" (PISSOLATO, 2007, p. $321)$.
}

Espaço Ameríndio, Porto Alegre, v. 6, n. 2, p. 10-31, jul./dez. 2012. 
AMANDA CRISTINA DANAGA - Os Tupi Guarani da Aldeia Renascer (SP)...

logo que esse terminou, mas algum tempo depois, quando o cenário estava abandonado e o local vazio. Ao encerrarem-se as gravações a área ficou abandonada. Não houve a construção de um "Centro Cultural" e nem o desmanche do cenário. Os índios começaram a frequentar as grandes ocas cenográficas. Algum tempo depois, sob a liderança de Awá, ocuparam o local. Segundo relatos, os critérios que foram relevantes para ocupação do local foram: a abundância da mata, a existência de água pura, a disponibilidade de materiais usados na confecção dos artesanatos, e uma forte identificação com o local, aconselhado através de um sonho (da mãe de Antonio Awá) como uma terra boa para se viver.

\section{$* * *$}

Afinal, o que representou esse filme para os índios e qual a sua afinidade com a realidade das pessoas que passaram a viver no local a partir de seu cenário?

Nos discursos do grupo, parece que a imagem proporcionada pelo filme e até mesmo a participação neste não foram os fatores mais significativos para a formação da aldeia. É claro que o filme teve grande importância, já que a comunidade se constituiu em seu cenário, mas isso não fica tão evidente assim nos depoimentos dos moradores da aldeia Renascer. O fato é que não se pode deixar de observar a presença da relação que a comunidade tem com a câmera e a preocupação com o registro das imagens. Se isso foi resultado ou não do contato com uma produção cinematográfica, não se sabe ao certo. O que se pode afirmar é que eles se valem constantemente dos recursos audiovisuais para registrar tudo que acontece em sua comunidade, ressaltando sempre a importância do armazenamento dessas imagens. Há um "arquivo" de fotos e reportagens sobre a aldeia, desde sua formação até os dias atuais. Existe também um blog (criado por eles) que está disponível na internet e que conta um pouco sobre a história da aldeia ${ }^{7}$. Durante todo meu trabalho de campo, a câmera fotográfica deles, que era também filmadora, esteve ligada. Enquanto eu registrava o que eles (moradores

\footnotetext{
${ }^{7}$ Para consultar o blog, acesse: http://aldeiarenascer.blogspot.com .
} 
AMANDA CRISTINA DANAGA - Os Tupi Guarani da Aldeia Renascer (SP)...

de Renascer) me diziam, eles registravam o que eu (pesquisadora) Ihes questionava. Enquanto eu tirava fotografias, era também fotografada.

\section{O uso da imagem: um diálogo com os de fora}

Ao elencar a aldeia Renascer como foco de análise da minha pesquisa etnográfica realizada durante o mestrado, além do contato com os Tupi Guarani do litoral e do interesse em pesquisar a formação destas aldeias, bem como suas demandas e reivindicações, o que me atraiu para a aldeia Renascer foi a questão do envolvimento com o filme. Entender como uma aldeia real surgiu a partir de uma aldeia cenográfica e qual a influência que o filme teve nesse processo, visto que o mesmo trabalhou com uma memória indígena de séculos atrás, eram minhas indagações iniciais para este trabalho.

Teria o filme despertado (através do acesso a uma memória coletiva que remeteu a um passado distante) algum sentimento que fez com esse grupo decidisse retomar uma terra, considerada por eles, tradicional? A imagem obtida por meio das filmagens poderia ter potencializado esse evento?

Por ser concreta, por lidar com emoções, a imagem
catalisa representações preexistentes, presentes no
imaginário de cada povo. Seu impacto sensível
permite que as imagens anteriores sejam
reconstruídas, atualizadas e refixadas de forma nova
(GALLOIS e CARELLI, 1995, p. 63).

O filme, protagonizado por alguns deles, tinha como personagens os antigos índios Tupi da costa, nos quais os Tupi Guarani reconhecem alguma origem. Há uma relação entre o "mito de origem" dos Tupi Guarani com os personagens vividos no filme. Talvez os Tupi Guarani não explicitem a relevância do filme no processo de formação da aldeia, pois isso poderia gerar um caráter de ficção ou artificialidade à sua ocupação, deslegitimando-a. Mas é fato que o filme tematizava seus supostos ancestrais tupi. De qualquer modo, a conexão entre a participação no filme, representando os antigos Tupi, e o desejo de formação da aldeia em nenhum momento foi enunciada pelos Tupi 
AMANDA CRISTINA DANAGA - Os Tupi Guarani da Aldeia Renascer (SP)...

Guarani da aldeia Renascer.

Ao chegar à aldeia Renascer com todas estas indagações, fui surpreendida pela pequena atenção que davam aos assuntos relativos ao filme. Este só era citado durante narrativas de fatos que, segundo eles, eram mais importantes para entender a história de formação da aldeia. Alguns nem sequer haviam assistido ao filme e não possuem nenhuma cópia do mesmo na aldeia.

Contudo, na continuidade de minha pesquisa, notei o quanto a comunidade estava interessada em registrar (seja por meio de vídeos, fotos etc.) tudo o que se passava na aldeia. O dia a dia do trabalho de campo era registrado, as andanças nas matas ao redor da aldeia eram registradas, as visitas às casas, cachoeiras, reuniões, rezas, entre outros, tudo era registrado o tempo todo. A presença da câmera representava uma constante na aldeia Renascer.

A preocupação inicial que me conduziu à aldeia Renascer, analisar o que o filme representou na vida daquelas pessoas e na formação da aldeia, foi modificada na medida em que todo o trabalho realizado em campo era gravado e que eu, pesquisadora, me tornava uma imagem. Esse processo permitiu considerar o importante papel que as tecnologias (arquitetadas no mundo dos nãoíndios) têm quando apropriadas pelos índios. Elas se tornam valiosas ferramentas de reflexão e mediadoras das relações entre o sujeito pesquisado e o pesquisador/antropólogo em campo.

$\mathrm{Na}$ "antropologia compartilhada", como a proposta por Jean Rouch, o sujeito investigado "experimenta a câmera" juntamente com o pesquisador, transformado-a em um objeto epistemológico. A filmagem e a edição do vídeo se tornam uma experiência para o próprio nativo, já que ele participa ativamente desse processo. Rouch, através da "antropologia compartilhada", legitimou o filme enquanto um objeto de reflexão metodológica, na medida em que ele contém certa subjetividade do nativo. Essa nova forma de fazer antropológico buscou construir um discurso reflexivo e comunicativo na relação entre o pesquisador e o pesquisado (SZTUTMAN, 2004).

Mas, no caso em pauta, não se trata de um fazer antropológico no qual o pesquisador se vale da imagem como um recurso metodológico para sua pesquisa, nem de uma imagem produzida 
AMANDA CRISTINA DANAGA - Os Tupi Guarani da Aldeia Renascer (SP)...

"compartilhadamente" entre o pesquisador e o pesquisado. Aqui, a imagem é produzida pelo próprio nativo com recursos (máquinas e filmadoras) próprios. O nativo produz a sua própria imagem e, mais ainda, a imagem do antropólogo, que passa a levar em conta não as imagens em si, mas este processo de fabricação das imagens. A imagem etnográfica, neste caso, pode ser vista como uma expressão da interação de uma nova relação entre o pesquisador e o pesquisado.

E o que leva os índios de Renascer a produzirem imagens? Por que esse desejo em registrar o cotidiano da aldeia?

Antonio Awá, o cacique da aldeia, mostrou sua preocupação em registrar os acontecimentos, como forma de guardar, de passar para as gerações futuras como foi o processo de demarcação territorial da área, como acontecem as danças e cantos, etc. Ele ainda nos descreve que aquilo que buscam com a veiculação das imagens da aldeia é o reconhecimento da comunidade pelo pessoal da cidade e por todo mundo, fator que representa fortalecimento para o grupo.

Analisada sob este ponto de vista, a produção/veiculação de imagens representa uma forma de traçar um diálogo com aqueles que vivem fora da aldeia, ou seja, com o mundo dos não índios. Os Tupi Guarani da aldeia Renascer - mais do que os Guarani Mbya, que mostram-se constrangidos diante das câmeras e da possibilidade de manuseá-las - estão registrando suas imagens como forma de estabelecer um diálogo com os não índios, nesse caso, os de fora.

Existem múltiplas formas de se constituir um diálogo com os de fora, como por meio de textos, com a produção de vídeos, gravação de CDs, dentre outras maneiras. Mas, geralmente, ele vem ligado a processos de luta política, reconhecimento dos outros, reflexão sobre si mesmo, valorização do grupo, busca de prestígio simbólico frente a outros grupos etc. Esta criação da produção de imagens de si, que os índios estão realizando na produção de vídeos, relaciona-se com a busca por maior visibilidade, tanto no cenário político nacional quanto em outros contextos.

Ao buscarem maiores benefícios para suas comunidades, os indígenas se engajam em um amplo universo de projetos que os projetam para fora, isto é, que os tornam mais visíveis diante da sociedade. É nesse "mundo dos projetos" que a "cultura" emerge. 
AMANDA CRISTINA DANAGA - Os Tupi Guarani da Aldeia Renascer (SP)...

Macedo (2009, p. 202) sinaliza que, para seus interlocutores da aldeia Ribeirão Silveira, dentro desse contexto da criação e participação de projetos e eventos, a "cultura" representa "[...] um modo novo e desafiante de continuar vivendo conectado e separado dos juruâ".

Além disso, o armazenamento das imagens e a criação dos vídeos representam uma forma de registrar aspectos que dão visibilidade à organização social de um grupo, a mitologia, o xamanismo, o saber tradicional, as histórias do contato, dentre outras características que permitem que haja uma transmissão do conhecimento, marcados por uma tradição oral. Isto revela uma contribuição para a valorização e o aprendizado da cultura por aqueles que são mais novos. Ao registrarem, os índios estão também "se resguardando".

A produção de vídeos e imagens, em geral, não é uma produção voltada somente para os de dentro, ela assume expectativas em relação aos olhares daqueles que estão de fora.

[...] falar de cultura com aspas não significa perpetuar uma dualidade entre cultura para dentro e cultura para fora, mas chamar a atenção para o fato de que a cultura se enuncia, sempre, imediatamente, entre o dentro e o fora (COELHO DE SOUZA, 2010, p. 108).

A câmera tem sido usada como um meio de se estabelecer um diálogo na objetificação do sujeito dentro deste processo de produção de imagens de si, além de ter se tornado um instrumento recorrente entre aldeias de todo o país. Para Gallois e Carelli (1995), a possibilidade do uso do vídeo faz parte de um processo que é inovador e encontra-se ligado com a produção cultural dos grupos, visto que estimula uma reelaboração constante da cultura.

[...] o acesso ao vídeo amplia as possibilidades de comunicação, internas e externas, entre grupos indígenas os registros em vídeo são principalmente utilizados em duas direções complementares: para preservar manifestações culturais próprias a cada etnia, selecionando- se aquelas que desejam transmitir às futuras gerações e difundir entre aldeias e povos diferentes; para testemunhar e divulgar ações empreendidas por cada comunidade para recuperar 
AMANDA CRISTINA DANAGA - Os Tupi Guarani da Aldeia Renascer (SP)...

seus direitos territoriais e impor suas reivindicações (GALLOIS e CARELLI, 1995, p. 63).

Os índios não querem só registrar, mas demonstrar aos outros (índios e não índios) suas histórias de vida e a realidade de suas comunidades. Deste modo, os povos indígenas estão articulando suas próprias imagens, as imagens que eles querem que todos vejam sobre quem eles são e o que eles fazem, principalmente dentro de um cenário de luta política e disputas por reconhecimento simbólico.

E é justamente neste contexto que está inserida a aldeia Renascer. Também engajada em um projeto de fortalecimento da "cultura" de seu povo, recorrendo ao uso das câmeras, celulares, blogs etc., para fazer de sua aldeia um cenário que pode ser visto por todos, a fim de mostrar como vivem e quem são os Tupi Guarani e os Guarani Mbya da aldeia Ywyty Guaçu8.

\section{A aldeia Ywyty Guaçu e o "renascer" da "cultura"}

[...] se Awá morre e não passa nada? Se eu morro e meus filhos crescem sem passar sua cultura, não é culpa deles, é culpa do velho, ele que não ensinou nada aos jovens (Informação verbal de Antonio Awá, Aldeia Renascer, 2010).

Em Renascer, o uso constante da câmera na captura de imagens, sejam elas fílmicas ou fotográficas, na tentativa de não deixar passar nada do que acontece na aldeia, está diretamente atrelada à invocação da "cultura". A busca por direitos territoriais, respeito e reconhecimento têm levado esses índios a exaltarem a sua "cultura", demonstrando-a de modo performático à sociedade nacional, como um recurso étnico e político, mas também como uma reflexão sobre sua própria singularidade. Nesse ponto refiro-me ao trabalho Carneiro da Cunha (2009), no qual a autora apresenta o conceito de "cultura" - entre aspas - como uma noção reflexiva desse

\footnotetext{
${ }^{8}$ Vale mencionar que o momento no qual realizei meu campo na aldeia Renascer também era marcado por um contexto de reivindicação e reconhecimento territorial. Eu, enquanto pesquisadora, também estava vinculada ao Grupo de Trabalho que realizava o relatório de fundamentação antropológica da área, o que pode indicar uma relação com a ênfase no registro de imagens.
} 
AMANDA CRISTINA DANAGA - Os Tupi Guarani da Aldeia Renascer (SP)...

termo, evidenciando que a ideia de cultura existe no âmbito de qualquer coletivo que busque formular sua diferença, a qual pode ser representada performaticamente para outros grupos.

Como advertiu Kelly (2005, p. 221) ao falar sobre os Yanomami em suas relações com os brancos, não se trata de uma performance vista como uma "teatralidade estratégica", mas sim como "uma ação intencional que visa fazer com que as pessoas respondam em um sentido determinado".

O discurso que envolve o fortalecimento da "cultura" na aldeia Renascer é corrente e vem ligado ao uso das câmeras em um processo no qual o "[...] audiovisual assume uma contribuição fundamental para os próprios índios - à medida que eles adquirem consciência e refletem sobre seus processos de mudança" 9 .

O agenciamento efetuado pelos índios diante do conceito de cultura e outros conceitos utilizados pela antropologia não é algo que é comum apenas à aldeia Renascer, mas um fator que está presente em muitas outras aldeias no Brasil e em comunidades nativas em todo o mundo.

Ao tratar dos Guarani Mbya e dos Tupi Guarani da aldeia Rio Silveira (SP), Macedo (2009) nos oferece um panorama de como esses mesmos índios, em constante contato com os brancos, passaram a agenciar o discurso da cultura a seu favor.

[...] até a década de 70 as posições de branco e índio eram predominantemente agenciadas sem que a cultura, como a identidade de povo ou etnia vinculada a um conjunto de tradições, fosse enunciada como uma categoria muito relevante no manejo das relações naquela região. A partir de então, em uma conjuntura nacional que inclui a criação de ONGs de apoio às causas indígenas no final da década de 70 e os debates pré-Constituinte a partir de meados dos anos 80 , os Guarani começam a contar com apoiadores articulados na reivindicação da posse regularizada das terras, e então a "cultura" passa a operar como categoria-chave e motor de controvérsias, incluindo acusações de serem índios sem cultura (MACEDO, 2009, p. 43).

\footnotetext{
${ }^{9}$ Entrevista gravada em 30 de abril de 2010 no estúdio Cine \& Vídeo - São Paulo/SP (Disponível em http://www.producaocultural.org.br/slider/vincent-carelli/).
}

Espaço Ameríndio, Porto Alegre, v. 6, n. 2, p. 10-31, jul./dez. 2012. 
AMANDA CRISTINA DANAGA - Os Tupi Guarani da Aldeia Renascer (SP)...

A cultura (com aspas), dentro desse contexto, funciona como um operador que agencia relações, "tanto pela produção de coisas como de pessoas (singulares e coletivas), ou de posições pelas quais as pessoas se percebem". Dessa forma, objetificar a "cultura", é o mesmo que realizar uma "objetificação da diferença" (MACEDO, 2009, p. 297).

A discussão levantada acerca da busca de uma autodenominação Tupi Guarani por índios que residem na costa litorânea do estado de São Paulo é mais um caso apontado que remete aos usos de alguns conceitos, antes restritos aos antropólogos, pelos povos indígenas. Observa-se como na atualidade os povos entre os quais fazemos nossas pesquisas têm se referido aos conceitos de cultura, identidade, tradição, entre outros. A intensificação do uso destes conceitos está, geralmente, conectada à busca por investimentos e benefícios políticos e/ou simbólicos, em que interlocutores não compartilham as mesmas premissas, mas se valem das mesmas palavras.

Como salientou Sahlins (1997a e 1997b), o que vem acontecendo são processos de autoconsciência cultural, de exigência política, de povos reassumindo suas identidades e da apropriação das inovações tecnológicas, de acordo com ordens cosmológicas específicas, sempre a favor da cultura. Com tudo isso, torna-se importante levar em consideração os usos destes conceitos como também conceitos nativos, já que estão sendo apropriados pelos índios. Ou ainda, como observou Carneiro da Cunha (2009, p. 313), ressaltar o uso local que se faz da categoria cultura, lembrando que "a cultura de que falam os antropólogos não é a mesma da que falam os povos indígenas" e que cultura e "cultura" não pertencem ao mesmo universo do discurso.

O uso das aspas, de acordo com a observação de Coelho de Souza (2010), não remete a uma purificação do nosso conceito de cultura, mas sim como um enunciado utilizado para enfatizar o uso da cultura para eles [os índios]. O uso da cultura seria um "efeito do encontro" com o não índio.

Quando usam nossa palavra - ou alguma tradução engenhosa dela - eles estão produzindo um objeto que significa sua relação conosco, mas trata-se ainda da produção deles: o que eles devem estar fazendo - eles não tem alternativa - não é objetificar sua cultura (sem 
AMANDA CRISTINA DANAGA - Os Tupi Guarani da Aldeia Renascer (SP)...

aspas) por meio do nosso conceito, mas sua relação conosco por meio dos conceitos deles - quero dizer, por meio de sua própria compreensão do que constitui criatividade, agência, subjetividade (COELHO DE SOUZA, 2010, p. 112).

$\mathrm{Na}$ aldeia Renascer, além do uso das câmeras e da internet no que se refere à apropriação do conceito de cultura na interface do diálogo com o mundo dos não índios, realizando o que Carneiro da Cunha chama de um processo de indigenização da "cultura", temos outros exemplos de promoção dessa visibilidade "cultural" (CARNEIRO DA CUNHA, 2009, p. 314).

Em abril do ano de 2004, a aldeia promoveu uma grande festa que contou com a participação de parentes vindos de outras aldeias e do público juruá do município de Ubatuba. Os índios denominaram o evento de Festa Indígena e relataram que mais de 600 indígenas de todas as aldeias do estado de São Paulo e alguns do Rio de Janeiro participaram do evento. Houve a apresentação de cantos e danças, comidas típicas, encontro entre pajés etc.

Cristiano Awá Kirindju disse que, inicialmente, fariam apenas um campeonato de futebol para celebrar o Dia do Índio, mas pediram auxílio para a Prefeitura Municipal e conseguiram ampliar o evento e dar a ele um caráter mais cultural, garantindo uma grande cobertura da mídia. Para Cristiano, a festa teve boa repercussão e auxiliou no processo de fortalecimento da "cultura" e no reconhecimento da comunidade por parte das pessoas que residem na cidade.

Mostramos para o município que não somos posseiros,
que não íamos destruir tudo e sim preservar nossa
"cultura" e nosso espaço. Agora eles sabem quem
somos e até nos ajudam. Nós fomos mudando nossa
imagem e hoje somos reconhecidos (Informação verbal
de Antonio Awá, Aldeia Renascer, 2010).

Essa festa, além de reforçar os laços entre os parentes, evidenciando a rede existente entre as aldeias Tupi Guarani da região, teve como intuito provocar alguma reação no público juruá, nesse caso, o reconhecimento de que aqueles que vivem na aldeia Renascer têm uma "cultura", uma língua, valores e costumes que são coisas de índio e que devem ser respeitados e reconhecidos pela comunidade local. A 
AMANDA CRISTINA DANAGA - Os Tupi Guarani da Aldeia Renascer (SP)...

realização desse evento garantiu uma maior visibilidade ao grupo da aldeia Renascer.

No estado de São Paulo, a busca por direitos territoriais, por projetos e parcerias em iniciativas diversas tem levado os índios a exaltarem e refletirem sobre sua "cultura". A questão do "apelo à cultura" tem sido usada como um recurso étnico e político e está na fala de muitas lideranças indígenas atualmente.

Segundo Macedo (2009), "[...] a novidade da "cultura" foi a demanda por conferir visibilidade, substantivar essa diferença, nem que seja pela retórica do "resgate" (MACEDO, 2009, p. 297).

A articulação da noção de "cultura" com a noção de "resgate" é criticada pelos índios de Renascer. Eles ressaltam que não se trata de resgatar uma cultura que, em algum momento, se perdeu, mas sim de um engajamento em um processo onde a "cultura" é revigorada. "Não estamos resgatando nada, quem resgata é quem perdeu algo, estamos sim fortalecendo a nossa cultura" (Cristiano, Aldeia Renascer, 2010).

Há ainda outro conceito que aparece conectado ao de "cultura", é o conceito de "natureza", que "opera como outra palavra mágica no mundo dos projetos" (MACEDO, 2009, p. 2). Este conceito aparece, sobretudo, quando os índios ocupam posições estratégicas no desenvolvimento sustentável. O discurso que abarca a ideia de proteção da natureza pode ser notado nas falas dos moradores de Renascer, lembrando que esta é uma aldeia que se vale de alguns recursos disponíveis na Mata Atlântica (uma área de preservação ambiental). Projetos ligados à extração sustentável, planos de manejo, preservação da área, entre outros são sempre citados dentro de contextos acerca do discurso sobre a "natureza".

\section{Considerações finais}

Conforme venho notando no trabalho etnográfico, o fenômeno atribuído à busca por uma autodenominação Tupi Guarani remete a uma reflexão que toma o conceito de cultura em sua acepção "com as aspas". 
AMANDA CRISTINA DANAGA - Os Tupi Guarani da Aldeia Renascer (SP)...

A cultura com aspas é autorreflexiva e diz respeito a uma consciência de si.

No caso dos Tupi Guarani residentes na costa paulista e também no interior do estado, observa-se que a busca por uma autodenominação é definida no interior de um contexto de autorreflexão sobre sua singularidade em relação aos brancos e a outras parcialidades guarani, no qual a "cultura" aparece com intensidade. Ser Tupi Guarani não articula uma noção de índio ressurgido ou de reemergência cultural, mas de uma reflexão sobre o fenômeno da cultura. Há clareza por parte dos índios do litoral sobre a existência dos Tupinambá, que habitavam a costa do Brasil. No entanto, eles não se dizem simplesmente e unicamente descendentes de tais Tupinambá. Eles advertem que são parte de uma mistura que resulta do casamento entre os últimos Tupinambá residentes no litoral paulista com os migrantes Guarani, que vieram para a costa em busca da Terra sem Males, e os não índios. Portanto, Tupi Guarani é uma reflexão que está atribuída ao uso da "cultura", não se tratando de uma identidade que ressurgiu, mas sim de uma autodenominação criada no contexto de enunciação da "cultura". Logo, a questão que envolve o agenciamento de uma denominação Tupi Guarani vai além de identificar se há ou não uma espécie de "continuidade" entre os antigos Tupi que viviam na costa litorânea e os atuais Tupi Guarani. O agenciamento da denominação Tupi Guarani remete a uma busca por inteligibilidade nos espaços onde estão não índios. Nesse ínterim, aparece a "cultura", como uma forma de articulação de elementos que visam demonstrar à sociedade não índia a nossa cultura, a nossa tradição [dos índios].

Nesses termos, a cultura (refletida com aspas) como aquela que os povos indígenas projetam para fora, para os outros, constitui-se como um desdobramento de uma relação histórica que é uma constância dos povos ameríndios: a relação com a alteridade. "[...] a relação com o exterior é parte do componente inato do mundo vivido indígena" (KELLY, 2005, p. 218).

[...] a forma mais eficiente de fortalecer a autonomia de um grupo é permitir que se reconheça, demarcando-se dos outros, numa identidade coletiva [...]. A cultura - que não é feita apenas de tradições - só existe como movimento, alimentado pelo contato com a alteridade (GALLOIS e CARELLI, 1995, p. 62). 
AMANDA CRISTINA DANAGA - Os Tupi Guarani da Aldeia Renascer (SP)...

\section{Referências bibliográficas}

CARNEIRO DA CUNHA, Manoela. Cultura e cultura: conhecimentos tradicionais e direitos intelectuais. In: Cultura com aspas e outros ensaios. São Paulo: Cosac Naify, 2009. p. 311-373.

CLASTRES, Hélène. Terra sem mal: o profetismo Tupi-Guarani. São Paulo: Editora Brasiliense, 1978.

COELHO DE SOUZA, Marcela. A vida material das coisas intangíveis. In: COELHO DE SOUZA, Marcela; COFACCI DE LIMA, Edilene (Orgs.). Conhecimento e Cultura: práticas de transformação no mundo indígena. Brasília: Athalaia Gráfica e Editora, 2010. p. 97-118.

GALLOIS, Dominique Tilkin; CARELLI, Vicent. Vídeo e diálogo cultural: experiência do projeto vídeo nas aldeias. Horizontes Antropológicos, Porto Alegre, v. 1, n. 2, p. 61-72, jul./set. 1995.

KELLY, José Antonio. Notas para uma teoria do "virar branco". Mana, Rio de Janiero, v. 11, n. 1, p. 201-234, 2005.

LADEIRA, Maria Inês. Aldeias livres Guarani do litoral de São Paulo e da periferia da capital. In: MONTEIRO, John Manuel et al. (Orgs.). Índios no estado de São Paulo: resistência e transfiguração. São Paulo: Yankatu/CPI, 1984. p. 123-144.

Espaço geográfico Guarani-Mbya: significado, constituição e uso. São Paulo: EDUEM, 2008.

LADEIRA, Maria Inês; AZANHA, Gilberto. Os índios da Serra do Mar: a presença Mbya Guarani em São Paulo. São Paulo: CTU/Nova Stella, 1988.

MACEDO, Valéria Mendonça de. Nexos da diferença: cultura e afecção em uma aldeia Guarani na Serra do Mar. 2009. 331 f. Tese (Doutorado em Antropologia Social) Universidade de São Paulo, [2009].

MAINARDI, Camila. Construindo proximidades e distanciamentos: etnografia da terra indígena Tupi Guarani de Piaçagüera/SP. 2010. 96 f. Dissertação ( Mestrado em Antropologia Social) - Universidade Federal de São Carlos, [2010].

MELLO, Flávia Cristina de. Mbya e Chiripá: identidades étnicas etnônimos e autodenominações entre os Guarani do Sul do Brasil. Revista Tellus, Campo Grande, v. 7, n. 12, p. 49-65, abr. 2007.

PEGGION, Edmundo et al. Estudos complementares da terra indígena Piaçaguera. 
AMANDA CRISTINA DANAGA - Os Tupi Guarani da Aldeia Renascer (SP)...

CGID/FUNAI, 2008. (Trabalho técnico).

PEREIRA, Luiz Alberto. Hans Staden mostra os dentes no cinema. Folha de São Paulo, São Paulo, p. 5-11, 17 mar. 2000. Folha Ilustrada. Disponível em: http://acervo.folha.com.br/fsp/2000/3/17/21. Acesso em: 09 jun. 2011.

PISSOLATO, Elizabeth. A duração da pessoa: mobilidade, parentesco e xamanismo Mbya (Guarani). São Paulo: Editora da UNESP, 2007.

SAHLINS, Marshall. O pessimismo sentimental e a experiência etnográfica: por que a cultura não é um objeto em vias de extinção? Mana, Rio de Janeiro, v. 3, n. 1, p. 41-74, 1997a.

O pessimismo sentimental e a experiência etnográfica: por que a cultura não é um objeto em vias de extinção? Mana, Rio de janeiro, v. 3, n. 2, p. 103-150, 1997 b.

SCHADEN, Egon. Aspectos fundamentais da cultura Guarani. São Paulo: EDUSP, 1974.

SZTUTMAN, Renato. Jean Rouch, um antropólogo-cineasta. In: CAIUBY NOVAES, Sylvia et al (Orgs.). Escrituras da imagem. São Paulo: Edusp, 2004, p. 49-62.

VIVEIROS DE CASTRO, Eduardo. Araweté: os deuses canibais. Rio de Janeiro: Zahar, 1986.

Os pronomes cosmológicos e o perspectivismo ameríndio. Mana, Rio de Janeiro, v. 2, n. 2, p. 115-144, 1996.

Espaço Ameríndio, Porto Alegre, v. 6, n. 2, p. 10-31, jul./dez. 2012. 